\title{
Corrigendum to "Explore the Conflict and Resolution of Pollution NIMBY Facility Construction in the Context of New Media: An Evolutionary Game Theoretical Approach"
}

\author{
Jie Yu $(\mathbb{D}$, Changzheng Zhang $(\mathbb{D}$, Dechun Huang, Yujia Shao $\mathbb{D}$, and Hong Ren \\ Business School, Hohai University, Nanjing 211100, China \\ Correspondence should be addressed to Changzheng Zhang; zcz@hhu.edu.cn \\ Received 11 November 2021; Accepted 11 November 2021; Published 11 December 2021 \\ Copyright (c) 2021 Jie Yu et al. This is an open access article distributed under the Creative Commons Attribution License, which \\ permits unrestricted use, distribution, and reproduction in any medium, provided the original work is properly cited.
}

In the article titled "Explore the Conflict and Resolution of Pollution NIMBY Facility Construction in the Context of New Media: An Evolutionary Game Theoretical Approach" [1], the Acknowledgements section should be added as follows:

\section{Conflicts of Interest}

The authors declare that they have no conflicts of interest.

\section{Acknowledgments}

This work was supported by the National Natural Science Foundation of China (nos. 71603070 and 71573072) and the Ministry of Education of Humanities and Social Science of China (no. 16YJC630172).

\section{References}

[1] J. Yu, C. Zhang, D. Huang, Y. Shao, and H. Ren, "Explore the Conflict and resolution of pollution NIMBY facility construction in the Context of New Media: an evolutionary game theoretical Approach," Complexity, vol. 2021, pp. 1-19, Article ID 9978968, 2021. 